\title{
Parents' psychological readiness as a condition for psychological safety of an inclusive educational environment
}

\author{
Elena Slusareva ${ }^{1, *}$, Natalja Mizina ${ }^{1}$, Aleksej Dontsov $^{1}$ \\ ${ }^{1}$ Stavropol state pedagogical Institute, Stavropol, Russia
}

\begin{abstract}
The article presents scientific approaches to the phenomenon of psychological safety of an inclusive educational environment. As one of the basic conditions for the psychological safety of an inclusive educational environment, the psychological readiness of parents of children with disabilities is considered: its structural components (cognitive, emotional, conative) and their content, due to the specifics of joint education of children with typical and atypical development. The relationship between the level of psychological readiness of parents and the level of psychological safety of an inclusive educational environment has been theoretically substantiated and empirically confirmed. Among the indicators of the psychological readiness of parents of children with disabilities, contributing to ensuring the psychological safety of an inclusive educational environment, the following is considered: active participation of parents in building the educational route of a child with disabilities, knowledge about the special educational needs of their own child, special conditions corresponding to these needs, emotionally positive attitude and satisfaction with interaction with subjects of an inclusive educational environment, protection from psychological violence of parents and children with disabilities as a central feature of a comfortable inclusive educational environment.
\end{abstract}

\section{Introduction}

At the present stage of the formation of education, including inclusive education, the assessment and attitude of the subjects of the educational process to the quality of education and the educational environment in which the child lives is gaining priority.

It should be noted that the assessment of the educational environment is carried out, first of all, by parents, who are the primary "customers" of educational services. Because of this, parents can significantly influence the policy of education both on the national scale and on the scale of a particular educational institution. The attitude of parents to the educational environment in an educational institution and the processes that take place in it - is one of the most important criteria for the effectiveness of the work of this institution and education as a whole. The researchers note that the assessment of parents primarily affects the efficiency and development of the educational institution [2, 5, 9, 10,14].

\footnotetext{
*Corresponding author: slusareva2005@yandex.ru
} 
One of the primary characteristics of an educational institution - is the educational environment. By definition S.V. Krivykh, the educational environment is an integral qualitative characteristic of the internal life of an educational institution, which is determined by specific tasks [12]. The educational institution defines and implements these tasks in its activities. The educational environment is manifested in the choice of the means by which the main tasks are performed. A meaningful assessment of the educational environment is formed according to the effect in the personal, social, and intellectual development of students, which is achieved through the child's stay in this educational environment. The educational environment of an educational institution can be considered as a set of information resources, teaching technologies and educational process support, which are implemented in the context of common principles of construction and provide a full cycle or a part of it, logically completed [4, 6]].

It should be noted that today the topical topic of studying the quality of the educational environment in an educational institution is the topic of its psychological safety. Today we can say that the problem of the psychological safety of the educational environment has emerged as a separate area of psychological knowedge [3].

According to I.A. Baeva, safety indicators are one of the main psychological parameters of the educational environment of a school. Psychological safety is understood by the author as the state of the educational environment, free from manifestations of psychological violence in interaction, contributing to the satisfaction of the needs for personal-confidential communication, creating a reference significance of the environment and ensuring the mental health of the participants included in it [2].

A psychologically safe educational environment is, according to the researcher, the environment that ensures the safety of the psyche of the subjects of the educational process, their high satisfaction and protection from psychological violence. This state, which characterizes the educational space, is fixed through the relations of the subjects of this space. As the key characteristics of the psychological safety of the educational environment, researchers most often highlight: the absence of manifestation of psychological violence in the interactions of the participants; the formation of a psychologically comfortable atmosphere in the team, which determines the referential significance and involvement of each of the subjects in the design and maintenance of the psychological comfort of the educational environment; providing an educational process that contributes to the effective functioning of each of its subjects, and which is focused on developing their skills to build psychologically safe relationships and minimize those risks that arise $[2,13]$.

I.A. Baeva reveals in detail the concept of psychological safety of the educational environment. The author presents this concept as a system of views, allowing to ensure the safety of participants from threats to positive development and mental health in the process of interaction in the educational environment. Within the framework of this concept, the author notes that the threat to psychological safety is ... non-recognition of the referential importance of the educational environment by its participants and, as a consequence, the realization of the intention to leave it or the denial of its values and norms. Hence ... the criterion of the psychological safety of the educational environment is its referential significance, recorded as an attitude towards it - positive, neutral or negative " [2].

Thus, the threat to psychological safety will be the lack of satisfaction with the basic indicators of the process of interaction of all subjects of the educational environment (including parents), since it is this satisfaction that contains the opportunities and conditions that ensure the personal development of all participants in the pedagogical process [3]. Empirical manifestations can be: emotional comfort, the ability to express one's opinion, the attitude of respect for oneself, the preservation of personal dignity, the ability to seek help, taking into account personal problems and difficulties, attention to questions and suggestions [15]. 
This position is shared by N.G. Rassokha, highlighting among the psychological characteristics of the educational environment of the school, which contribute to the preservation and provision of its psychological safety, high parental involvement, satisfaction with the relationship with the rest of the subjects of the educational process of parents as participants in the educational environment of the school. It is necessary that any effort aimed at preserving and ensuring the psychological safety of the educational environment of the school is supported by both the students themselves, teachers, the administration, and parents. Psychologically safe interpersonal relationships contribute to the formation of ideas about psychologically safe interaction and are reflected in the formation of the personality of all subjects. In this case, interpersonal relations are determined by N.G. Rassokha as a system of attitudes, orientations and expectations of all subjects of the educational environment of the school in relation to each other [13].

G.S. Korytova and E.Yu. Zakotnova also believe that a psychologically safe educational environment can be considered an environment in which the majority of participants have a positive attitude towards it, they have a high level of satisfaction with the indicators of the educational environment and there is a high degree of protection from psychological violence in interpersonal interaction [11].

Considering the issues we have highlighted in the format of an inclusive educational environment, we can say that the attitude of parents to an inclusive educational environment, their satisfaction with relationships with other subjects of the educational process as participants in the educational environment and their involvement, participation are indicators of the measure of recognition by parents of the referential significance of an inclusive educational environment, its values and norms [15]. And this, in turn, as we have shown above, is one of the safety criteria for an inclusive educational environment.

T.N. Adeeva, I.N. Simaeva, V.V. Khitryuk, L.S. Yagovkina and other researchers have shown that the involvement (complicity) of parents of different categories of students, based on the attitude of parents to an inclusive educational environment, on their satisfaction with relationships with other subjects of the educational process, is ensured by the willingness of parents to teach children together in an inclusive educational environment. This allows the inclusive educational environment to be safe and to solve its primary task - socialization and social integration of all students [1, 14, 16,17].

Thus, we can consider the psychological readiness of parents of different categories of students to coeducate children in an inclusive educational environment as one of the conditions that ensure the psychological safety of this environment. In this article, the psychological readiness of parents of children with disabilities will be considered as such a condition.

\section{Materials and methods}

In the conditions of inclusive education, the role of parents in the educational process increases and has both general characteristics and differentiated ones, based on the subjective position of parents in the inclusive educational process. Hence, the most appropriate definition of the phenomenon of parents' psychological readiness for inclusive education of children with disabilities, in our opinion, is the concept of parental readiness, which is considered as consistent in the cognitive, emotional and conative components of intentions that precede and determine the nature of their interaction and communication in conditions of an inclusive educational space [14].

The active participation of parents in building the educational route of a child with disabilities, knowledge of the special educational needs of their own child, special conditions that meet these needs, an emotionally positive attitude and satisfaction with interaction with 
subjects of an inclusive educational environment are important conditions for the effectiveness of inclusive education.

The content of the psychological readiness of parents of children with disabilities is reflected in the "readiness of parents to assist in the education of children with disabilities" [17]. We define the psychological readiness of parents for the inclusive education of children with disabilities as a systemic education, consisting of the knowledge and ideas of parents about the variability of educational routes of a child with disabilities (the cognitive component of readiness); practical skills in building this route and assistance in building it in an inclusive educational environment (conative component) and emotionally positive attitude to inclusive educational practice (emotional component of readiness).

Summarizing the work of researchers in this area the following structural components of this formation can be distinguished $[1,14,16,17]$ :

1. The cognitive component is represented by the totality of knowledge and ideas of parents of children with disabilities about inclusive education. This component in our study is represented by two blocks of knowledge:

- first block: the formation of parents' knowledge in the field of inclusive education: knowledge and understanding of what inclusive education is and how it differs from other forms of education; knowledge of the main regulatory documents in the field of inclusive education (Laws of the Russian Federation, Standards, etc.); knowledge of the forms and options for teaching a child with disabilities (special, integrated, inclusive education; knowledge of options for adapted basic programs, etc.);

- second block: knowledge about the special educational needs of your own child, due to the typological characteristics of dysontogenetic manifestations and individual psychological characteristics of his personality, as well as special educational conditions that are necessary for the child (organization of psychological, medical and pedagogical support, additional classes with a defectologist, etc.)

2. The emotional component of readiness is represented by such characteristics as: the attitude of parents to inclusive educational processes; the degree of satisfaction with the main characteristics of an inclusive educational environment and interactions in this environment; state of protection from psychological violence, satisfaction of basic needs in personal and confidential communication.

3. And the final structural component of psychological readiness is conative or behavioral - the actions of parents aimed at optimizing interaction in an inclusive educational environment, the formation of practical skills to assist in the education of their own child with disabilities.

Thus, the psychological readiness of parents for the inclusive education of children with disabilities is considered by us as a state of readiness (together with the teacher as the leading subject of educational relations and the support service specialists) to build the educational route of their own child. The psychological readiness of parents is a systemic education consisting of the parents' knowledge about the child's educational route (the cognitive component of readiness); practical skills in building this route (conative component) and an emotionally positive attitude to inclusive educational practice (emotional component of readiness).

In accordance with the specified criteria, we have selected and adapted a set of diagnostic methods: methodology "Interviewing parents of children with disabilities"; a questionnaire on the attitude of parents to the conditions of inclusive education (G.V. Zhigunova); assessment of an inclusive educational environment for students' parents (S.A. Kalashnikova); methodology for assessing the psychological safety of the educational environment of the school (adaptation of the methodology of I.A. Baeva) $[2,7,8]$. 
The experimental study was carried out on the basis of an educational organization that has been implementing inclusive educational practice for more than 15 years. The study involved 50 parents of children with disabilities.

\section{Research results}

An analysis of the parents' personal data made it possible to note that in most cases, mothers are engaged in the educational trend of the child ( $84 \%$ of those who took part in the survey were women). The parents' age ranged from 25 to 50 years, the most represented age - from 36 to 40 years (37\%). Most of the parents have higher education (72\%). The nosological diagnosis of a child is known to most of the parents and is presented in the following qualitative and quantitative equivalents: children with impaired functions of the musculoskeletal system (ICP) - 33\%, children with autism spectrum disorders - $12 \%$, children with hearing impairment $-7 \%$, children with mental retardation $-5 \%$, with mental retardation - $2 \%$. It should be noted that there is a fairly high percentage of those who abstained (37\%), which may be due both to the parent's ignorance of the characteristics of their own child, and also to the unwillingness to provide this information.

The study of the cognitive component of readiness, which consisted of two blocks of questions and statements, showed that most of the parents do not know (42\%) or know only about 1-2 educational organizations that implement adapted basic general educational programs for children of different nosological groups (hearing, vision, speech, dysfunction of the musculoskeletal system, etc.) in the Stavropol Territory (40\%).

When asked about the type of educational organization in which their own child studies, only $21 \%$ of parents answered that this is a general education school in which children with disabilities study. Most of the parents (51\%) answered that their children are enrolled in a general education school with separate classes for children with disabilities. $28 \%$ of parents refrained from answering, which may indicate the lack of formation of ideas about the educational organization in which their own child studies.

Similar data were obtained on the question about the form of education of the child: $16 \%$ of parents know that this is inclusive education in a regular classroom of a general education school. Most of the parents answered that the child will study in a separate class according to the adapted basic general education program (AGEP) (35\%) and in a separate school for students with disabilities according to AGEP (30\%). Individual / homeschooling was mentioned by $50 \%$ of parents.

Only $23 \%$ of parents know what an adapted basic compulsory program and a version of the $\mathrm{ABCP}$ of their own child are. Most parents do not know about the program their child is studying in (67\%). Most of the parents know about the extra activities of their own child. The maximum representation of answers according to the statements "attends correctional classes (speech therapist, psychologist, defectologist) - 93\% and regularly attends school holidays and other events $-67 \%$.

A similar position of parents in the answers concerning the provision of psychological and pedagogical assistance to the child by specialists of the psychological and pedagogical support service: most of the parents (95\%) noted that the child receives such assistance in the form of classes with an educational psychologist (84\%); a speech therapist (81\%), teacherdefectologist $-67 \%$. Parents also noted the presence of other types of assistance in the form of adaptive physical education, massage, etc. (58\%).

Assessing the quality of assistance provided in an educational organization, most of the parents assess it as high (56\%) and average (37\%), which indicates a high level of parental satisfaction with the educational and correctional services provided.

The second block of questions touched on knowledge about the special educational needs of the child, his individual characteristics, special approaches and methods due to these 
characteristics. The answers received show that knowledge about the interests of their own child, as well as about his difficulties in studying certain subjects, is formed by only a small part of parents $(30 \%)$.

Thus, most of the parents noted the child's interest in mathematics (21\%) and the Russian language $(19 \%)$. At the same time, the parents noted special difficulties in the same subjects: in the field of mathematics - 30\%, Russian - $21 \%$. When asked what hinders the child's education, most of the parents found it difficult to answer (53\%). The same high percentage of those who abstained when answering the question about the conditions for improving the quality of education of children with disabilities $-67 \%$ of those who abstained.

In our opinion, this may be due to the low level of reflexive analysis by parents of the reasons for the difficulties of their own child, the lack of ideas about the conditions that he needs to be included in the educational process of a general education school.

Whereas when concretizing the special educational needs of children and special educational conditions in the form of direct questions, we obtained higher percentages. Thus, the availability of knowledge about special approaches and methods in teaching children with disabilities was noted by $86 \%$ of respondents; understanding of the need to teach children according to adapted basic general education programs - $93 \%$.

When asked what the parent was guided by when choosing an educational organization, most of the parents answered "with their views on the child's health and capabilities" - 79\%, with the recommendations of the psychological-medical-pedagogical commission (PMPC) $30 \%$, with the recommendations of medical workers - $19 \%$.

Interesting are the parents' answers to the projective question "My child is a person who ...". The data we received, which we conditionally divided into several groups:

- a group of answers related to the acceptance of the general and specific in the child's development: "as usual, but with his own interests" (14\%), "has the right to a full life" (12\%), "everything can be done if he is helped" ( $9 \%)$; "perceives the world in a very peculiar way" $(2 \%)$, "likes to study, but requires special attention" (2\%), "special, but very kind and sociable" (2\%);

- a group of answers related to emotional assessment: "does not need pity, but tolerance" $(6 \%)$, "knows that he is loved and appreciated, and also support in overcoming difficulties" $(2 \%)$, "needs attention and care, we love him very much "( $2 \%)$," wants to be happy, worthy of love and respect $(6 \%)$, etc.

Of the popular forms of interaction with parents, parents noted the following: consultations by a psychologist or social teacher at school - 58\%; conversations and consultations with the class teacher - $44 \%$. Whereas the traditional form of interaction parenting meetings - is one of the unclaimed forms of work with parents of children with disabilities (19\%).

When asked about the optimization of the joint education of children, most of the parents refrained from answering - $63 \%$, the answers of the rest of the parents concerned the increase in the informativeness of teachers and healthy children about children with disabilities - $12 \%$.

The study of the emotional component of the psychological readiness of parents of children with disabilities involved the study of satisfaction, the attitude (positive, negative, indifferent) of parents to inclusive educational practice and the state of psychological safety of the child and parent in an inclusive educational environment.

Parental satisfaction with the main components of an inclusive educational environment was studied using a survey method. The quantitative assessment was carried out by ranking the indicators according to the degree of preference (from the most preferred to the least). A qualitative assessment of the indicators was presented by polar assessments: from noncompliance (dissatisfaction) to full compliance (complete satisfaction).

In the initial analysis, attention is immediately drawn to the fact that the quantitative indicators of parents are dominated by the answers "complete satisfaction" - $82 \%$. The 
ranking of indicators showed that parents are most satisfied with the socio-psychological component of an inclusive educational environment, which is reflected in a favorable psychological climate, the comfort of being at school, etc. (89\%). The second rank place $(82 \%)$ is represented by satisfaction with the spatial-subject component of the environment: architectural design, information accessibility, etc. The third rank place was assigned to the psychodidactic component of the inclusive educational environment (81\%): content, methods, technologies for teaching a child, the presence of a support system, additional education. And the last - the fourth rank place (76\%) - is the subject component of the environment, which manifests itself in the subject-subject interactions of the participants in educational relations, their subject characteristics: satisfaction with the interaction of parents with other participants in educational relations, satisfaction with the level of professional training of teachers and support service specialists.

The study showed a high level of parental satisfaction with the subject position in an inclusive educational environment $-80 \%$. The highest rates were noted by us for such interaction strategies as "the participation of parents in the discussion of the individual educational route of the child" $(100 \%)$ and "the participation of parents together with specialists in determining the basic educational program of their children and optimal psychological and pedagogical technologies adequate to the child's capabilities" (100\%). The least satisfaction was received by such indicator as "the participation of parents in assessing the dynamics of their child's development" (52\%).

The study of parental attitudes allowed us to note that the most significant for them are positive relationships with teachers "(49\%), then - relationships with students with disabilities $(23 \%)$, with the parents of children with disabilities" $(19 \%)$. The presence of "emotional comfort" in the relationship was noted by the majority of parents $(56 \%)$. In general, the attitude of the parents is viewed as positive.

Studying the final indicator of the emotional component of readiness - the protection of parents and children from violence in an inclusive educational environment, we noted that the facts of a negative attitude towards a child with disabilities were noted in $30 \%$ of cases and manifested themselves in the form of "calling peers" (33.5\%), "ignoring the child" (11\%). In turn, the study of the state of psychological security of parents of children with disabilities in interactions with teachers, the administration of the educational organization showed that parents assess their security quite high (the indicators were distributed from 89 to $95 \%$ ). The highest quantitative indicators were obtained for such characteristics as: protection from ridicule $(95 \%)$, from threats, insults, from what will be forced to do without the parents' desire (92\%).

And the final component - conative - involves the study of the formation of practical skills in promoting inclusive education: the use of methods, forms and methods of work used in the educational organization, in interaction with the child in the family; actions of parents aimed at optimizing the inclusive education of children with disabilities.

It should be noted that when studying this component of readiness, we obtained the smallest quantitative indicators: only $12 \%$ of parents expressed their readiness to help in working with their own child, $8 \%$ noted cooperation with teachers and the transfer of educational methods to family practice (for example, the introduction of alternative communication in interaction with the child both at school and at home). $5 \%$ of parents noted their full assistance to their child in everything. And 2\% said that their actions directly depend on the needs of the school.

\section{Discussion}

The study of the cognitive component of the psychological readiness of parents shows a pronounced contradiction between the parents' knowledge of the need to create special 
educational conditions for their child and a low level of awareness about the educational route of their own child. The obtained quantitative indicators make it possible to assess the level of cognitive readiness of parents of children with disabilities as insufficient.

The study of the emotional component of the psychological readiness of parents showed a positive attitude towards inclusive educational practice, a high level of satisfaction with relationships and an inclusive educational environment; psychological safety of children and their parents. This component has the highest level of formation.

The most pronounced difficulties were identified by us when assessing the conative (behavioral) component of parental readiness. Most often, parents raising children with disabilities shift the center of responsibility from their own actions outside - to teachers, methodological support of the educational process, which may be due to the unwillingness of parents to take responsibility for the quality of joint learning.

\section{Conclusions}

The data obtained allows us to note that:

1. One of the conditions for ensuring the safety of the educational environment in an inclusive educational institution is the psychological readiness of parents for joint education of all categories of students in an inclusive educational space. In this context, the psychological readiness of parents is considered as their readiness, manifested at the level of all components (cognitive, emotional and conative), for functional (safe) interaction with other subjects of the inclusive educational space. This readiness, in our opinion, is an indicator of the degree of recognition by parents of the referential importance of an inclusive educational environment, its values and norms. And this, in turn, is one of the safety criteria for an inclusive educational environment.

2. The psychological readiness of parents for the inclusive education of children with disabilities can be considered as a systemic education, consisting of the knowledge and ideas of parents about the variability of educational routes of a child with disabilities (the cognitive component of readiness); practical skills in building this route and assistance in building it in an inclusive educational environment (conative component) and emotionally positive attitude to inclusive educational practice (emotional component of readiness).

3. Our research revealed a mismatch in the formation of the components of the parents' psychological readiness. The empirical data obtained allow us to note that the emotional component predominates in the structure of the psychological readiness of parents of children with disabilities: demonstrating outwardly social acceptance of the idea of joint learning, a high level of satisfaction with the main components of an inclusive educational environment (socio-psychological learning conditions, material, technical and content-methodological conditions educational organization) and a positive attitude towards it, the parents are still not sufficiently prepared for the effective component (insufficient involvement of parents in building the educational route of their own child). Such a mismatch in the formation of the components of the system of psychological readiness of parents is due to an insufficient level of cognitive readiness: parents have insufficiently formed ideas about the methods and forms of interaction with their own child, they cannot transfer the existing knowledge into the practice of interacting with a child, preferring the help of support service specialists.

Thus, our research has shown the need to form the psychological readiness of parents of children with disabilities for joint learning, and, first of all, its cognitive and conative components. 


\section{References}

1. T.N. Adeeva, Siberian Pedagogical Journal 4, 112 - 119 (2016)

2. I.A. Baeva, Psychological safety in education (Publishing house "SOYUZ", SPb, 2002)

3. I.A. Baeva, V.V. Semikin, Bulletin of Practical Psychology of Education 3(4), 7 - 19 (2005)

4. E.P. Belinskaya, O.A. Tikhomandritskaya, Social psychology of personality (AspectPress, M., 2001)

5. I.A. Brown, Safety of the educational environment: psychological assessment and support (MGPPU, M., 2013)

6. S.S. Gordeeva, Perm University Bulletin. Philosophy. Psychology. Sociology 27 (2016) https://cyberleninka.ru/article/n/suschnost-i-struktura-sotsialnoy-ustanovki-vsotsiologii-i-sotsialnoy-psihologii

7. G.V. Zhigunova, Yu.V. Kuznetsov, I.Yu. Salmina, A.N. Kuznetsov, Study of the tolerance of various groups of the population towards children with disabilities (Publishing house of MSTU, Murmansk, 2008)

8. S.A. Kalashnikova, Education and training 4, 60-67 (2015)

9. I.E. Kondrakova, School management 17, 1 - 15 (2009)

10. I.E. Kondrakova, N.M. Fedorova, Humanitarian guidelines for educational policy and public administration in the field of school education (LLC "Book House", SPb, 2008)

11. G.S. Korytova, E.Yu. Zakotnova, Bulletin of TSPU 9(162), 96 - 102 (2015)

12. S.V. Krivykh, Izvestia AltSU (2010) https://cyberleninka.ru/article/n/sootnoshenieponyatiy-sreda-i-prostranstvo-v-sotsiokulturnom-i-obrazovatelnom-aspektah-1

13. N.G. Rassokha, Ideas about the psychological safety of the educational environment of the school and the types of interpersonal relationships of its participants $(\mathrm{SPb}, 2005)$

14. I.N. Simaeva, V.V. Khitryuk, Bulletin of the Baltic Federal University named after I. Kant 11, 54 - 62 (2015)

15. E. Slusareva, A. Dontsov, 2nd International Conference on Contemporary Education and Economic Development, 236-242 (2019) DOI: 10.23977/ceed.2019.038

16. E. Slusareva, A. Kabushko, A. Dontsov, SHS Web of Conferences 70, 10010 (2019) DOI: $10.1051 /$ shsconf $/ 20197010010$

17. L.S. Yagovkina, Pedagogical conditions for preparing parents to promote the education of children with disabilities (Khurgan, 2010) 